\title{
The Effect of Shade Trees in the Coffee Ecosystem to the Population and Diurnal Activity of Insect Pollinators
}

\author{
Supriyadi Supriyadi ${ }^{\mathrm{a}, 1}$, Fuady Dawam Dzikrillah ${ }^{\mathrm{a}, 2}$, Retna Bandriyati Arniputri ${ }^{\mathrm{a}, 3}$, Retno Wijayanti ${ }^{\mathrm{a}, 4}$ \\ ${ }^{a}$ Department of Agrotechnology, Faculty of Agriculture, Sebelas Maret University (UNS), Surakarta, 57126, Indonesia \\ E-mail: ${ }^{1}$ supriyadi58@staff.uns.ac.id; ${ }^{2}$ fuadydzikrillah@yahoo.co.id; ${ }^{3}$ retnowijayanti@staff.uns.ac.id; ${ }^{4}$ retnabandriyati@staff.uns.ac.id
}

\begin{abstract}
Insect pollinators is one of the important factors in the cross-pollination of coffee flowers, which affects the coffee fruit set. However, there is still a limited understanding of how shade trees in the coffee ecosystem affect insect pollinators. The purpose of this study was to obtain information on the effect of climate variations at different shading levels in the coffee ecosystem to the population and diurnal activity of insect pollinators. The shade levels are categorized in three ways, namely high shade, low shade, and open shade. The observation was conducted at the time when the flower blooms with sample units a flower in two coffee branches. Insect pollinators that show feeding behavior in coffee flowers were recorded in the morning, while the diurnal activity of each species pollinator was observed in the morning, midday, and afternoon. The study showed five species of insects belonging to three families and two orders, Hymenoptera and Lepidoptera that showed feeding behavior on coffee flowers. Apis cerana and Apis mellifera were the dominant pollinators of coffee flowers. The difference in shade levels did not affect pollinator species to visit coffee flowers, but their population tends to decrease in the open shade, except Apis cerana. The peak of diurnal activity of insect pollinator recorded in the morning decreased at midday and showed an increase slightly in the afternoon until the end of the diurnal activity. An increase of temperature may significantly decrease the number of pollinators that visit coffee flowers, while humidity and light intensity showed no significant effect.
\end{abstract}

Keywords — climate factors; level shade; species pollinator; flower bloom.

\section{INTRODUCTION}

Coffee (Coffea sp.) is one of the essential trade commodities, which places Indonesia as the fourth largest coffee exporter in the world, after Brazil, Vietnam, and Colombia [1], [2]. However, coffee production and exports from Indonesia often fluctuate [2], [3], because coffee cultivation practices have not been carried out intensively. One aspect of agronomic practice that needs a concern in coffee cultivation is the management of shade trees. The shade trees in the coffee ecosystem play an essential role in establishing the climatic factors that influence the increase in coffee productivity [4]-[7] and even the quality of coffee beans, especially caffeine content [8], but still poor management in Indonesia. The high productivity of coffee needs to be supported by a favorable environment that protects it from light intensity [6] and extreme temperatures. The shade trees serve to reduce the maximum and minimum temperatures, humidity, as well as light intensity [9]. Thus, microclimate factors are more established and favorable for coffee growth.

On the other hand, the pollination of coffee flowers is also an important key to increase coffee productivity [10]. The number of coffee bean yields may increase in line with the higher diversity and abundance of insect pollinators that visit during the blooming flower season [11]-[14], even increased by more than $50 \%$ compared to if only pollinated by the wind [15]. Biodiversity pollinators improve yields by $30 \%$ [14], those crop management strategies to conserve pollination services on a farm is needed. However, strategies to improve coffee flower pollination by encouraging environmentally friendly of insect pollinators on the coffee ecosystem in Indonesia are limited; meanwhile, the insect pollinators on a coffee flower may become very diverse. Insect pollinators belong to the order of Hymenoptera, Diptera, and Coleoptera in Mexican coffee plantation [13].

The relationship between shade trees and pollinator insects has not been studied in detail. Coffee shade trees also play an essential role in the life quality of insect pollinators. The total nitrogen content in coffee flower pollens protected by the shade is higher than that in coffee pollens that are exposed to light intensities [16]. The Nitrogen content in pollen may increase the life quality of insect pollinators for the sufficiency of their feed nutrition. Despite these benefits, there is still a limited understanding of how shade trees affect climate factors, as well as insect pollinator behavior. The coffee shade trees influence the climate factors, i.e., temperature, humidity, and light intensity around coffee 
[17], which may also influence the behavior and population of insect pollinators.

Therefore, it is essential to study the lack of a clear understanding of how interactions between shade trees of the coffee ecosystem and the population of insect pollinators. It is also vital to study regular activities in tropical climates, such as in Indonesia, needs to be studied. The objective of this study was to obtain information how the effect of variations in climatic factors (temperature, relative humidity, and light intensity) on different levels of coffee shade to pollinator populations and diurnal activity. The information on the relationship between shade trees and insect pollinators is vital to manage shade trees in coffee plantations, which will provide benefits, both for the growth of coffee and insect pollinators to increase coffee bean yield. This research also support as suggest to anticipation related to adaptation in climate change [18], in order to establish of coffee productivity.

\section{MATERIALS AND METHODS}

\section{A. Study Sites}

The study was conducted at the Tlogo Plantation, Tuntang, Semarang Regency, Central Java, Indonesia, which is located $110^{\circ} 28$ ' $11^{\prime \prime}$ East and $7^{\circ} 15$ '56" South, with an altitude of $480-600 \mathrm{~m}$ above sea level. The minimum daily temperature was $28^{\circ} \mathrm{C}$ and maximum at $34^{\circ} \mathrm{C}$, and the rainfall ranges from $1500-2800 \mathrm{~mm} /$ year. The coffee variety is Robusta (Coffea canephora Pierre ex A.Froehner) and the shade trees are white lead trees, Leucaena leucocephala (Lamk.) De Wit. and sunshine trees (Erythrina variegate L.).

\section{B. The Category of Coffee Shade and Weather Conditions Under Study}

Measured microclimatic factors, namely temperature, humidity, and light intensity for each coffee shade condition (high shade, low shade, and open shade) were conducted to identify each difference at the ground level. Measured temperature within the tree crown, relative humidity at $1 \mathrm{~m}$ above ground, and light intensity at the surface of coffee branches flowers (about 1.5). Data on temperature and relative humidity were collected by using a mobile digital thermo-hygrometer and light intensity was recorded by using a portable lux meter (HI 97 500; digital light-gauge range: 0.1-199.9 Klux) at a distance of about $1,5 \mathrm{~m}$ from the ground [19].

The weather conditions of coffee shade were categorized in three ways:

- High Shade: (1) Maximum temperature $28.8^{\circ} \mathrm{C}$, minimum $24.4^{\circ} \mathrm{C}$, average $27.7^{\circ} \mathrm{C}$; (2) Maximum humidity $75 \%$, minimum $59 \%$, and average $65 \%$ (3). Maximum light intensity 16,855 Lux, minimum 3,205 Lux, and the average of 11,891 Lux.

- Low Shade: (1) Maximum temperature $28.7^{\circ} \mathrm{C}$, minimum $24.5^{\circ} \mathrm{C}$ and average $28.6^{\circ} \mathrm{C}$; (2) Maximum humidity $71 \%$, minimum $56 \%$, and average $62 \%$ (3). Maximum Light Intensity 24,133 Lux, minimum 4,590 Lux and average 18,742 Lux.

- Open Shade: (1) Maximum temperature $30.3^{\circ} \mathrm{C}$, minimum $26.6^{\circ} \mathrm{C}$ and average of $29.1^{\circ} \mathrm{C}$; (2). Maximum humidity $67 \%$, minimum $58 \%$, and average 63\%; (3)
Maximum light intensity 27,772 Lux, minimum 9,925

Lux, and average 20,456 Lux.

\section{Insect Pollinator Population}

To assess the population of insect pollinators, 20 plants were randomly selected at each site of shade category, namely high shade, low shade, and open shade. Sample points were selected randomly of each site of shade category and selected the nearest plant for the next point. On each selected plant, the insect pollinators were recorded on two branches to perform observations of pollinator population, as well as the kinds of insect pollinator [20]. Observations of pollinators recorded visually in the morning, between at 07.30-09.30 a.m., during the bloom of a coffee flower, in line with their activity. The population abundance of each pollinator species was recorded on two minutes per each two branches sample unit by adopting a scan sampling method. The pollinator only considered as insects those floral visitors that contacted the sexual parts of the coffee flower and showed feeding activities. All pollinators were identified by using the key determination of insects.

\section{Effect of Climate Factors}

Measured microclimatic variables specific, including temperature, humidity, and light intensity, were carried out at the ground level (see II B). Meanwhile, each species of insect pollinator population was observed visually, like the procedure of II C. The population abundance of each pollinator species was recorded on two minutes per each two branches sample units. The perform observations of the population were carried out sequentially on the same day at all condition levels of shade trees to identify their relationship to microclimatic variables of temperature, humidity, and light intensity.

\section{E. Diurnal Activities of Insect Pollinators}

Diurnal activity of each species insect pollinator was also recorded on 20 plants randomly selected at each site of shade category, namely high shade, low shade, and open shade. On each selected plant, two branches of coffee were selected as a sample unit, modification of branch number [20], to record the pollinator activity. The perform observations of pollinator activity were carried out sequentially on the same day, i.e., in the morning (07:30 a.m. to $09: 30$ a.m.), midday (11:30 a.m. to $13: 30)$ and afternoon (14:30 to $17: 00)$, during the bloom of coffee flower to identify their diurnal activity of each species. Each species pollinator activity was recorded on 2 min per two branches sample.

\section{F. Data Analysis}

Data population of insect pollinators each at high shade, low shade and open shade were tested for normality and transformed as needed [21], and presented as an arithmetic \pm standard deviation in histogram using Excel 2013 (Window 10). Simple regression and simple correlation were estimated for the average population of insect pollinators and abiotic factors, viz. temperature, humidity, and light intensity, similarly the method [22], by using SPSS software (10.0J) for statistical analysis. Data on the diurnal activity of insect pollinators in high shade, low shade, and open shade 
are presented in graphics using Excel 2013 (Window 10) to identify its effect.

\section{RESUlTS AND DISCUSSION}

\section{A. Species and Populations of Insect Pollinator}

The research identified that coffee flowers were visited by five species of insect pollinators belonging to six genera, three families, and two orders of Hymenoptera and Lepidoptera. The insect pollinator recorded show feeding behaviors on coffee flowers. Two families in the Hymenoptera are Apidae and Halictidae, while one of the Lepidoptera orders is Pieridae. There are three species of the Family of Apidae, namely Apis cerana, Apis mellifera and Xylocopa pubcens, while the Halictidae recorded one species of Lasioglossum spp. Meanwhile, Colias hyale from the Family Pieridae. The (Lepidoptera) also showed feeding activity on coffee flowers $C$. hyale (Pieridae: Lepidoptera) is an herbivorous insect but is not recorded as a coffee pest. The species and population of insect pollinators that visit coffee flowers are shown in Table I.

The honey bees and wild bees (Hymenoptera) are known to play an important role in plant pollination [23] as well as on C. arabica and C. cenophora [20], [24]. Meanwhile, the butterfly (Pieridae: Lepidoptera), showed feeding behavior on coffee flowers, but their essential role as a coffee pollinator have not been reported in detail or may be a minor pollinator.
This study showed that the level of shade conditions in coffee (high shade, low shade, and open shade) did not affect insect pollinator species to visit the coffee flowers. The differences in shade conditions, as well as climate factors in the coffee ecosystem at the case of study site, have not disturbed the insect pollinator species to visit coffee flowers.

The study also showed that the population of insect pollinators of coffee flowers tends to decrease in the more open shade. The population of A. mellifera, X. pubcens, Lasioglossum spp., and $C$. hyale decreases with the open shade condition, except for A. cerana, which is not affected by the differences in shade levels. Manyuli [20] also recorded that a high shade conditions lead to the increase in the number of bee visits to coffee flowers

Vergara and Badano [13] show that the diversity of insect pollinators may be influenced by the management system implemented in coffee plantations. The diversity of insect pollinators species in rustic or traditional shade coffee with a high diversity of shade trees are 12 species, higher than four species of pollinators in coffee plantations under individual shade trees. The two specialized of shaded tree species in this coffee plantation, namely $L$. eucocephala and $E$. variegate may lead to low diversity of insect pollinator species. Unfortunately, this study did not record the effect of shade trees to the species diversity of wasp parasitoid (minute Hymenopteran) group, which also frequently visit the flowers, but not reported yet as an important pollinator.

TABLE I

THE SPECIES, POPULATION OF INSECT POLLINATORS DURING BLOOM OF COFFEE FLOWERS

\begin{tabular}{|l|l|l|l|l|l|c|}
\hline \multirow{2}{*}{ Ordo } & \multirow{2}{*}{ Family } & \multirow{2}{*}{ Genera } & \multirow{2}{*}{ Species } & \multicolumn{3}{|c|}{ Coffee Shade Trees /Population per branch/2 min. } \\
\cline { 4 - 7 } & & & & High Shade & Low Shade & \multicolumn{1}{c|}{ Open Shade } \\
\hline \multirow{3}{*}{ Hymenoptera } & \multirow{2}{*}{ Apidae } & \multirow{2}{*}{ Apis } & Apis cerana F. & $5.29 \pm 1.43$ & $5.00 \pm 2.19$ & $3.57 \pm 0.95$ \\
\cline { 3 - 7 } & & & Apis mellifera K. & $3.29 \pm 1.03$ & $1.50 \pm 0.54$ & $2.71 \pm 0.93$ \\
\cline { 3 - 7 } & & Xylocopa & Xylocopa pubescens S. & $0.14 \pm 0.08$ & $0.32 \pm 0.17$ & $0.29 \pm 0.08$ \\
\cline { 3 - 7 } & Helictidae & Lasioglossum & Lasioglossum sp. & $0.14 \pm 0.08$ & $0.71 \pm 0.10$ & $0.14 \pm 0.14$ \\
\hline Lepidoptera & Pieridae & Colias & Colias hyale L. & $0.57 \pm 0.25$ & $0.26 \pm 0.19$ & $0.43 \pm 0.43$ \\
\hline
\end{tabular}

\section{B. Proportions of Abundance of Each Species in Pollinator Assemblages}

The diversity of insect pollinator species in all shade tree conditions was not different, but their abundance may be affected by shade conditions. The Proportion of the abundance of insect pollinators on the bloom of coffee flowers under different shade tree conditions is shown in Fig.1. Overall, the proportion of abundance of insect pollinator assemblages in high shade is $38 \%$, higher than abundance in low shade $(31 \%)$, and an open shade $(31 \%)$. This showed that shade trees tend to increase the visit of insect pollinators in coffee flowers than coffee without shade trees. Coffee shade trees, however, may provide a suitable environment for insect pollinators to visit. This shows how important shade trees to conserve the ecosystem of coffee to increase coffee pollination to establish the yield of coffee beans. This is due to the overall effect of the different interactions between shade trees which depend upon in site conditions (soil/climate), a component of species or varieties, below ground and above ground characteristics of the shade trees and coffee [13]. Studies related to this topic in Indonesia are limited, therefore more detailed studies related to the role of shade trees are needed.

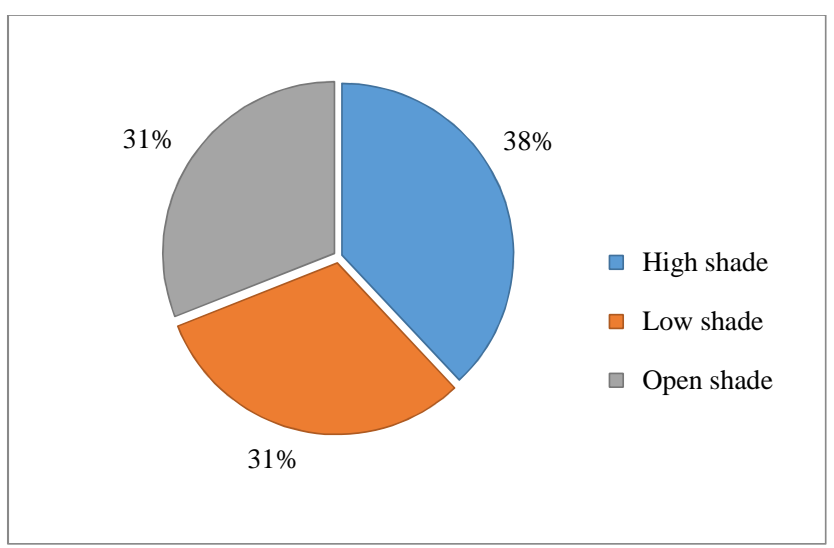

Fig.1. Proportions of the abundance of insect pollinators on bloom of coffee flowers under different shade tree conditions 
Among the five pollinator species recorded on a coffee flower, honey bee A. cerana and A. mellifera are the dominant species in the high shade, low shade and open shade. The proportions of each species of pollinator assemblages on bloom of coffee flowers under different shade tree conditions is shown in Fig.2.

The proportions of each species in pollinator assemblages in all three shade conditions was recorded: A. cerana $(53 \%$ in high shade to $64 \%$ in low shade) and A. mellifera ( $21 \%$ in the open shade to $36 \%$ in high shade), while other species of $X$. pubescens, Lasioglossum sp. and C. hyale were less than $10 \%$. The higher proportion abundance of $A$. cerena in coffee plantations without shade trees due to the low of $A$. mellifera visiting coffee under the open shade. Similarly, Apis mellifera is recorded as the dominant species (more than $80 \%$ of pollinator assemblages) under the different shade trees management systems in Mexican coffee plantations [13].

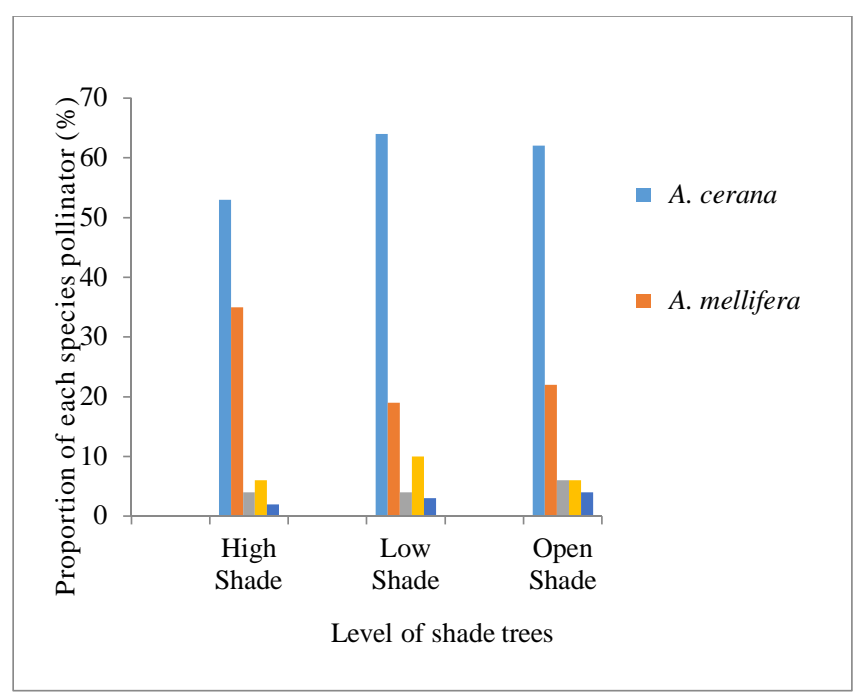

Fig. 2. Proportions of each species of pollinator assemblages on the bloom of coffee flowers under different shade tree conditions

\section{Effect of Climate Factors}

Based on simple linear regression and correlation analysis between the population of insect pollinators and temperature, showed a negative correlation and significant $\left(\mathrm{y}=-0.430 \mathrm{x}+33.634\right.$ by value of $\mathrm{R}^{2}=0.609 ; \mathrm{r}:-0.54 ; \mathrm{P}<$ $0.005)$. The regression analysis between the population of insect pollinators and the temperature is presented in Fig. 3.

The negative ( $\mathrm{r}:-0.54, \mathrm{P}$ value $<0.05$ ) of correlation coefficient showed that the average population of insect pollinators decreased by increasing temperatures in coffee ecosystem. The different results [22], recorded that Hymenopteran pollinators, viz. A. mellifera A. cerana, Lasioglossum sp., Xylocopa sp. were positively correlated with temperature. The geographical position of the study site which is located $34^{\circ} 5{ }^{\prime} 24^{\prime \prime} \mathrm{N}$, due to the different responses of these pollinator insects. This shows that establishing the temperature of the coffee ecosystem need to consider the geographical position.

The positive correlation between the population of insect pollinator and temperature (in the tropical ecosystem), indicates that the presence of shade trees is important for establishing favorable temperatures in the coffee ecosystem. The negative effect of temperature in the coffee ecosystem on insect pollinator populations is an important result related to management strategies the existence of a shade tree in the coffee ecosystem. Rasiska and Khairullah [26] also reported that shade trees in the coffee ecosystem establish the temperature and are beneficial to pollinator activities.

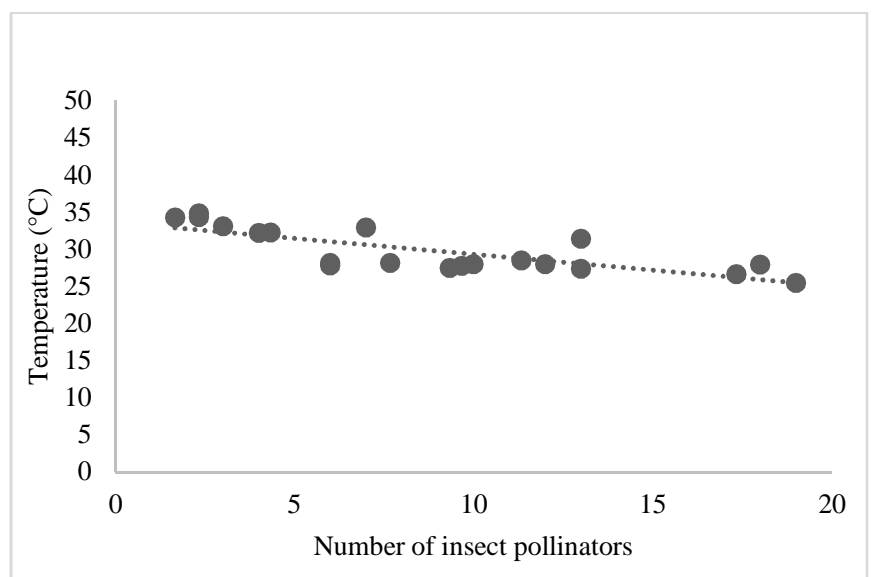

Fig. 3. Relationship between population of insect pollinator on coffee flower and temperature

Meanwhile, the simple linear regression and correlation analysis of relative humidity to average populations of insect pollinators showed a tendency to increase but was not significant $\left(\mathrm{y}=0.0145 \mathrm{x} \quad 0.398\right.$ by value of $\mathrm{R}^{2}=0.757$; $\mathrm{r}$ : $0.32 ; \mathrm{P}>0.005)$. The regression analysis between the population of insect pollinators and relative humidity is presented in Fig. 4.

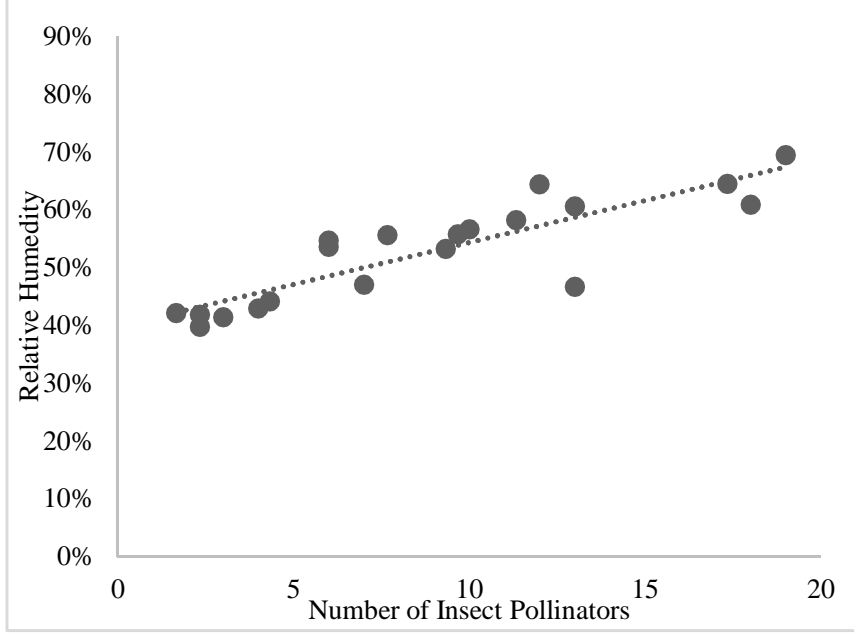

Fig. 4. Relationship between the population of insect pollinator on the coffee flower and relative humidity.

The positive correlation coefficient showed that the average population of insect pollinators increased but not significant by increasing relative humidity in the coffee ecosystem. The difference or variation of relative humidity at the study site ecosystem may not significantly affect the activity of insect pollinators. This relative humidity influences the flight activity of pollinator insects [29]. Altaf et al. [22] also noted that the activity of pollinators Hymenoptera and Lepidoptera was negatively correlated with relative humidity. Further research with more variation 
in shade levels with different humidity levels is needed to confirm the results of this study to achieve a suitable humidity level for visits and pollination activities in coffee flowers.

The regression and correlation analysis of the effect of light intensity showed that the population of insect pollinators slightly decrease by increasing light intensity, but the correlation was also not significant $(\mathrm{y}=-0.4297 \mathrm{x}+$ 33.634 , by the value of $\mathrm{R}^{2}=0.6089 ; \mathrm{r}:-0.22$; $\left.\mathrm{P}>0.005\right)$. The regression analysis result between the population of insect pollinators and light intensity is presented in Fig. 5.

The difference and variation of light intensity at the study site may not significantly affect the activity of insect pollinators to visit the coffee flower. However, relative humidity and light intensity affect insects, although the intensity of light affects their flight activity [29]. Light intensity, however, may not be a good attribute factor for the community of insect pollinator on coffee plantations, and their activity was positively correlated with the light intensity [22]. The light intensity may directly affect on the temperature of the ecosystem, thus establishing the light intensity is as essential as establishing temperature in the coffee ecosystem. Overall, the shade trees may contribute to an increase in the population of insect pollinators by establishing climate factors in the coffee ecosystem. Studies of interactions between climate factors and insect pollinators are still needed for anticipation and adaptation to climate change [27].

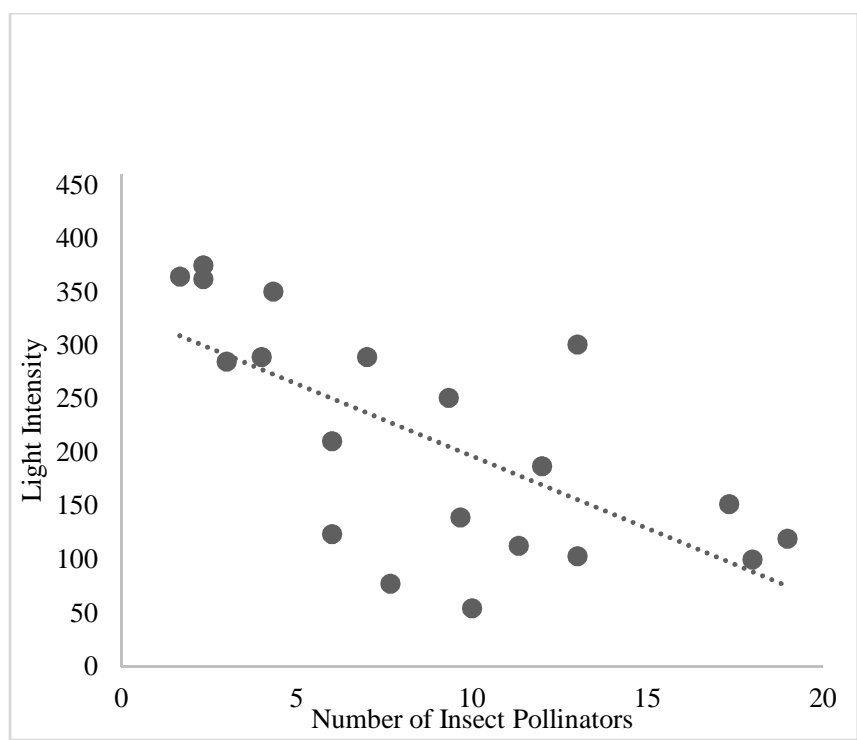

Fig.5. Relationship between the population of insect pollinator on a coffee flower and light intensity

\section{Diurnal Activities of Insect Pollinators in Coffee Flowers}

In general, the diurnal activity of insect pollinators, in coffee flowers during the blooming season, shows fluctuations, a rapid increase in the morning (07: 00-09: 00 a.m.) as well as the peak diurnal activity. At midday (11:00 a.m.-01:00 p.m.), the diurnal activity of insect pollinators decreased rapidly and then tended to increase slightly in the afternoon until the end of the diurnal activity. There is a difference in the diurnal activity of insect pollinators in coffee flowers. The diurnal activity of insect pollinators may increase by increasing the temperature and sunshine hours in the morning and decreasing due to an increase in high temperature and light intensity at midday, except $X$. pubescens, Lasioglossum sp. and $C$. hyale that slightly fluctuate due to low population.

The abundance of insect pollinator populations may be related to the diurnal activity. Bee pollinators, both $A$. cerana and $A$. mellifera, which were recorded with high population abundance (Table 1.), showed higher fluctuations of diurnal activity than $X$. pubescens, Lasioglossum sp. and $C$. hyale which low population abundance. The increased diurnal activity of insect pollinator also follows an increase of light intensity as well as temperature in the morning; then its activity decreases at the peak of increased temperature and light intensity in middy. However, the decrease in temperature and light intensity in the afternoon only slightly increases the diurnal activity of insect pollinators and lower than in the morning. Whether the high activity of insect pollinator, especially bees (Hymenopteran) in the morning related to the temperature or nectar flow in flowers or other factors needs to be studied. The diurnal activity of insect pollinators on coffee flowers under the different levels of coffee shade are presented in Fig. 5, 6 and 7.

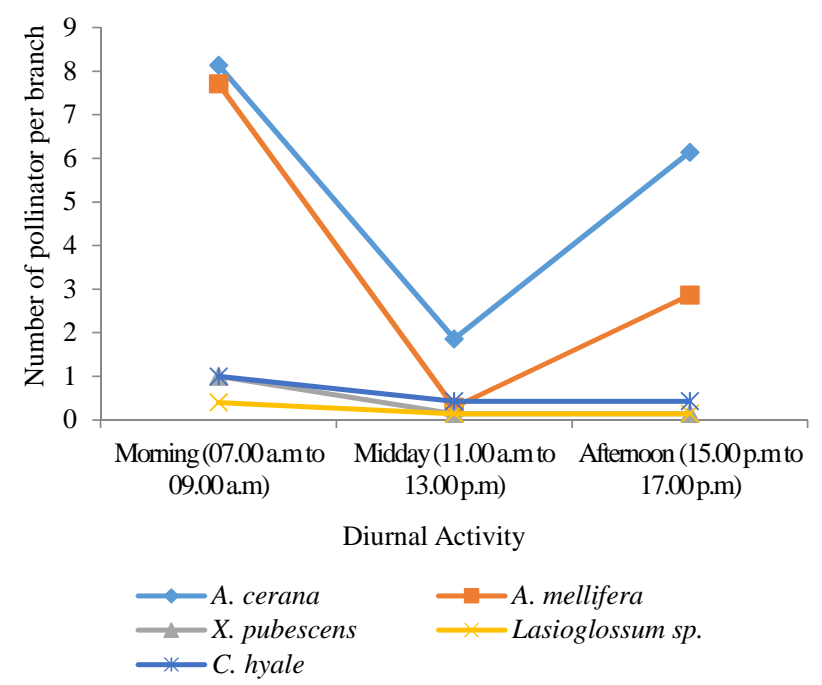

Fig. 6. The diurnal activity of insect pollinators under the high shade in the coffee ecosystem

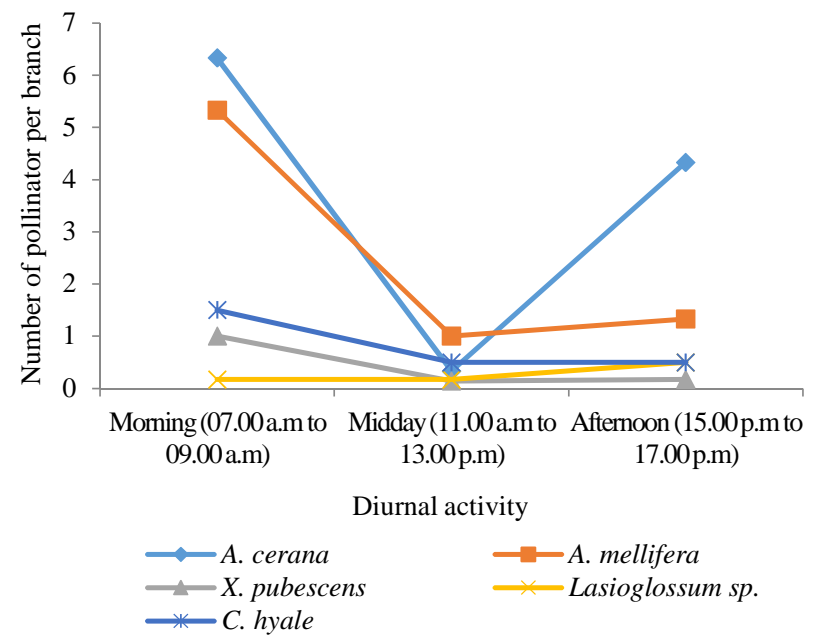

Fig. 7. The diurnal activity of insect pollinators under the low shade in the coffee ecosystem 


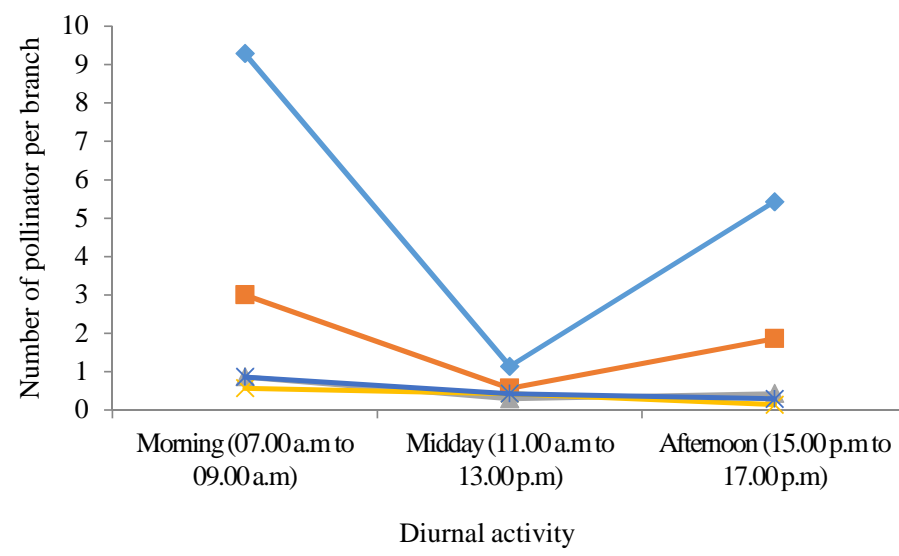

$\longrightarrow$ A. cerana
$\because$ X. pubescens
$\because$ - A. mellifera
- C. hyale

Fig. 8. The diurnal activity of insect pollinators under the open shade in the coffee ecosystem

This study showed that the diurnal activity of pollinator bees, especially A. cerana is influenced by the condition of shade trees, namely the activity in midday (figure $6,7,8$ ). The activity of $A$. cerena to visit coffee flower during the midday in the high shade is higher than at the same time in a more open place (open shade). The daily activity of bee pollinators, as social insects, is mainly related to activities such as the collection of pollen and nectar for their colonies. This is different from solitary pollinators such as Lepidopteran and Dipteran which only feed themselves.

Each kind of insect pollinator may also have different responses to climate factors changes, viz. temperature, humidity, and light intensity during the morning to evening. The effect of climatic factors on insect pollinators have been reported by some scholars [22], [29]-[30], which shows variations in the response patterns of activity and abundance of insect pollinators to temperature, light intensity, and relative humidity. Altaf et al. [22], for instance, reported that the peak of diurnal activity of Hymenopteran and Lepidopteran pollinators was recorded at noon between 12:00-14:00 p.m., in contrast to this study. This difference may be due to geographical position or altitude, which causes differences in temperature and sunshine hours.

Overall, the factors of geographical position, differences in sunshine hours, altitude, and shade trees may influence the time of temperature change, and the light intensity that are responded to insect pollinators. Therefore, studies related to the effect of microclimate factors in coffee ecosystems to diurnal activity may differ according to geographical position, altitude, including shade trees. This information is important to anticipate climate change to encourage the role of insect pollinators in the coffee production system in the future.

\section{CONCLUSION}

The differences of shade conditions in the coffee ecosystem did not affect species of insect pollinators that visit coffee flowers, but the population tends to decrease in the more open shade. Honey bees, A. cerana, and $A$. mellifera are the dominant species in all shade conditions. The study also recorded that the insect pollinator population decreased significantly by increasing temperatures, while the effects of relative humidity and light intensity were not significant. The shade trees may contribute to increasing the population of insect pollinators by establishing the climate factors in the coffee ecosystem. The diurnal activity of insect pollinators in coffee flowers showed an increase quickly in the morning, decreases rapidly at midday, and slightly increases in the afternoon until the end of the activity. The shade trees in the coffee ecosystem play important roles in encouraging the abundance and the diurnal activity of insect pollinators; thus, the existence in the coffee production system is needed. Management strategies related to the existence of shade trees in the coffee ecosystem are also an important part in anticipating climate change in the future coffee production system.

\section{ACKNOWLEDGMENT}

The Financial support of the research comes from the Directorate Research and Public service, Ministry of Research, Technology, and Higher Education of the Republic of Indonesia (DIPA Grant No. 474 /UN27.21/PP/2018).

\section{REFERENCES}

[1] Foreign Agricultural Service, USDA. (2018) Coffee: World markets and trade, December2018. [Online]. Available:https://downloads.usda.library.cornell.edu/usdaesmis/files/m900nt40f/41687n67f/nk322j622/ coffee.pdf.

[2] International Coffee Organization. (2018) Monthly Coffee Market report, December 2018. [Online]. Available: http://www.ico.org/documents/cy2018-19/cmr-1218-e.pdf.

[3] A. Meiri, R. Nurmalina, and A. Rifin, "Trade analysis of Indonesian coffee in international market". Jurnal Tanaman Industri dan Penyegar, vol. 4(1), pp.39-46, Mar. 2013.

[4] V. Boreux, P. Vaast, L.P. Madappa, K.G. Cheppudira, C. Garcia, and J. Ghazoul, "Agroforestry coffee production increased by native shade trees, irrigation, and liming". Agronomy for Sustainable Development. 36(42), pp.1-9, Jul. 2016.

[5] R. Cerda, C. Allinne, C. Gary, P. Tixier, C.A. Harvey, L. Krolczyk, L. Krolczyk, C. Mathiot, E.Clement, J.N. Aubertoti, and J. Avelino, "Effects of shade, altitude and management on multiple ecosystem services in coffee agro-ecosystems". European Journal of Agronomy, vol. 82, pp.308-319. Sep.2017.

[6] A. Agung and Shahabudin, "The effect of shading system against attacks of Conophomorpha cramerella (Gracillariidae: Lepidoptera) and Cocoa production in the cocoa plantations of Rahmat Village Palolo District". E-J Agrotekbis, vol. 2(3), pp.224-229, Jun.2014.

[7] S.G. Prado, "Resurgence of specialized shade coffee cultivation: Effects on pollination services and quality of coffee production". Agriculture, Ecosystems and Environment, vol. 265, pp.567-575, Jul.2018.

[8] K. Sherge, J. D'heer, L. Duchateau, and P. Boeckx, "Influence of growing altitude, shade and harvest period on quality and biochemical composition of Ethiopian specialty coffee". Journal of the Science of Food and Agriculture, vol.97, Oct. 2016.

[9] J. Beer, R. Muschler, D. Kass, and E. Somarriba. "Shade management in coffee and cacao plantations". Agroforestry Systems, vol.38, pp.139-164, Jul, 1998.

[10] L. Geeraert, R. Aerts, G. Berecha, G. Daba, N. De Fruyt, J. D'hollander, H. Kenny, S. Hanna, and H. Olivier, "Effects of landscape composition on bee communities and coffee pollination in Coffea arabica production forests in southwestern Ethiopia". Agriculture, Ecosystems \& Environment, vol. 288, Feb. 2020.

[11] A.M. Klein, I. Steffan-Dewenter, and T. Tscharntke, "Pollination of Coffea canephora in relation to local and regional agroforestry management", Journal of Applied Ecology, vol. 40(5), pp. 837-845. 2003 .

[12] H. Ngo, A. Mojica, and L. Packer, "Coffee plant- pollinator interactions: a review" Canadian Journal of Zoology, vol. 89(8), pp. 647-660, Jul. 2011. 
[13] C.H. Vergara and E.I. Badano, "Pollinator diversity increases fruit production in Mexican coffee plantations: The importance of rustic management systems". Agriculture, Ecosystems \& Environment, vol. 129, pp.117-123. Jan. 2009.

[14] J. Hipólito, D. Boscolo, and BF.Viana, "Landscape and crop management strategies to conserve pollination services and increase yields in tropical coffee farms". Agriculture, Ecosystems \& Environment, vol. 256, pp. 218-225, Feb. 2018.

[15] S. Krishnan, C.G. Kushalappa, R.U. Shaanker, and J. Ghazoul, "Status of pollinators and their efficiency in coffee fruit set in a fragmented landscape mosaic in South India". Basic and Applied Ecology, vol. 13, pp.277-285, Mar. 2012.

[16] S.G. Prado, J.A. Collazo, P.C. Stevenson, and R.E. Irwin, "A comparison of coffee floral traits under two different agricultural practices". Scientific Reports, vol. 9(1), pp.1-13, May. 2019.

[17] Y.A. Mariño, M.E. Pérez, F. Gallardo, M. Trifilio, M. Cruz, and P. Bayman, "Sun vs. shade affects infestation, total population and sex ratio of the coffee berry borer (Hypothenemus hampei) in Puerto Rico". Agriculture, Ecosystems \& Environment, vol. 222, pp. 258266, 2016.

[18] Y. Pham, K. Reardon-Smith, S. Mushtaq, and G. Cockfield, "The impact of climate change and variability on coffee production: a systematic review". Climatic Change, vol. 156(4), pp. 609-630, Sep.2019.

[19] W.P. Silva and M. Gimenes, "Pattern of the daily flight activity in two colonies of Nannotrigona testaceicornis (Lepeletier, 1836) (Hymenoptera, Apidae) in different conditions in the Brazilian semiarid region". Sociobiology, vol. 61(4), pp. 547-553, Dec. 2014.

[20] M.B.T. Munyuli, "Micro, local, landscape and regional drivers of bee biodiversity and pollination services delivery to coffee (Coffea canephora) in Uganda". International Journal of Biodiversity Science, Ecosystem Services \& Management, vol. 8(3), pp.190-203, May 2012.

[21] K. Gomez and A. Gomez. Statistical procedures for agricultural research. 2nd. New York: John Wiley and Sons Inc.; 1984
[22] S. Altaf, I.Ahad, and B. Za, "Relative abundance of insect pollinator and their correlation with important abiotic factors on almond". Journal of Entomology and Zoology Studies, vol. 5(4), pp.529-532, Jun.2017.

[23] Y.P. Paudel, R. Mackereth, R. Hanley, and W. Qin, "Honey bees (Apis mellifera L.) and pollination issues: current status, Impacts, and potential drivers of decline". Journal of Agricultural Science, vol. 7(6), pp.93-109, May 2015.

[24] D. Veddeler, A.M. Klein, and T. Tscharntke, "Contrasting responses of bee communities to coffee flowering at different spatial scales". OIKOS, vol. 112(3), pp.594-601, Mar.2006.

[25] V. Boreux, C.G. Kushalappa, P. Vaast, and J. Ghazoul, "Interactive effects among ecosystem services and management practices on crop production: pollination in coffee agroforestry systems", PNAS, vol. 110 (21), pp 8387-8392, May. 2013.

[26] S. Rasiska and A. Khairullah, "The effects of three types of shade trees on the diversity of insects in coffee plantation at Cilengkrang, Bandung". Agrikultura, vol. 28(3), pp. 161-166, 2017.

[27] A. Chain-Guadarrama, A. Martínez-Salinas, N. Aristizábal, and T.H. Ricketts, "Ecosystem services by birds and bees to coffee in a changing climate: A review of coffee berry borer control and pollination". Agriculture, Ecosystems \& Environment. vol. 280, pp. 53-67, Apr. 2019.

[28] M. DeSilva, M. Ramalho, and J.F. Rosa, "Why do the stingless bee Melipona scutellaris (Hymenoptera, Apidae) forage at high relative air humidity?" Iheringia, Série Zoologia, vol. 101(1/2), pp.131-137, 2011.

[29] W.N. Asiah-Wan Mohd Adnan, A.S. Sajap, N.A. Adam, and M.N. Hamid, "Flight intensity of two species of stingless bees Heterotrigona itama and Geniotrigona thoracica and its relationships with temperature, light intensity and relative humidity", Serangga, vol. 20(1), pp. 35-42, 2015.

[30] S.D. Hilário and M. de F. Ribeiro, V.L. Imperatriz-Fonseca, 'Can climate shape flight activity patterns of Plebeia remota (Hymenoptera, Apidae)?', Iheringia. Série Zoologia, vol. 102(3), pp. 269-76, 2012. 